\title{
Is it Any Wonder, I Reject You First: Pre-Pandemic Perceptions of K-12 Online Learning
}

\author{
Jason Paul Siko ${ }^{1}\left[\right.$. Michael Kristopher Barbour ${ }^{2}$
}

Accepted: 2 February 2022 / Published online: 24 February 2022

(c) Association for Educational Communications \& Technology 2022

\begin{abstract}
Similar to previous iterations, this action research study examined student perceptions of K-12 online learning as part of an action research project working to improve a graduate course on using internet-based instruction in the classroom. Additionally, since the data were collected prior to the COVID-19 pandemic, additional analysis of the qualitative data shines a light on why K-12 education struggled with the transition to remote teaching in the spring of 2020. Qualitative analysis of student artifacts, particularly student blog posts, revealed a general lack of awareness about the scope of online learning at the time, an evolving consensus of whether online learning was suitable for various ages, and how adults support online learning. Recommendations for future iterations of the course take these themes into account, along with how the pandemic may have already changed the opinions of future students in the course.
\end{abstract}

Keywords action research $\cdot \mathrm{K}-12$ online learning $\cdot$ pedagogy $\cdot$ teacher preparation

\section{Introduction}

Over the past three decades, K-12 online learning has grown at an accelerating rate (Barbour, 2019). While estimates can vary, a recent article in Forbes claimed that approximately 2.7 million students were doing some form of online learning prior to the COVID-19 pandemic (Schroeder, 2019). However, teacher preparation programs have been slow to change their curriculum to help pre-service and in-service teachers adapt their skills for teaching in this context (Archambault et al., 2016; Kennedy \& Archambault, 2012). This is despite recommendations from the U.S. Department of Education (2017) calling for the nation's educators to become more skilled in online and blended environments.

This lack of training became quite apparent during the COVID-19 pandemic, as almost every teacher in the United States had to convert their instruction to an online or blended

Jason Paul Siko

sikojp@gmail.com

Michael Kristopher Barbour

mkbarbour@gmail.com

1 Wayne County Regional Educational Service Agency, 33500 Van Born Road, Wayne, MI 48184, USA

2 Touro University, 1310 Club Dr, Vallejo, CA 94592, USA format almost overnight in the spring of 2020. Cavanaugh and DeWeese (2020) documented the struggle with a comparison of internet searches for topics related to online teaching in February 2020 versus March 2020, where the number of searches for phrases such as, "setting up the digital learning environment," went from roughly 100,000 in February to almost 4 million in March. Further, in their analysis of secondary teachers from around the world between March and May 2020, Howard et al. (2021) discerned four "profiles" of teachers with respect to their self-reported online readiness. Those with lower perceptions of their online readiness struggled to adapt, and the lack of institutional preparedness had a greater effect on their ability to adapt, more so than those with higher perceptions.

Given how the pandemic caught everyone off guard, there is little wonder as to why the $\mathrm{K}-12$ response to the shutdown was widely panned as a failure, with continued talk about recovering from the loss of learning that occurred (Engzell et al., 2021). While such an abrupt switch would understandably be problematic, it was clear that even with the forecast of schools being online for the 2020-21 school year, giving the teachers a summer to prepare for the change was woefully inadequate (Diliberti \& Kaufman, 2020; LaBonte et al., 2021). Further, while it is clear that the pandemic will eventually come to a close, threats of future pandemics and the increased frequency of natural disasters based on 
anthropogenic climate change force us to reckon with the high probability of future, albeit more localized, extended school closures (Barbour et al., 2020; Rush et al., 2016). Regardless of when it will happen again or what will cause it to happen again, the basic question of why systems were so unprepared remains. For example, in an article published in a popular media magazine Gen, German (2020) examined individual - some would say isolated - instances of jurisdictions who utilized more legacy forms of distance learning (such as correspondence education and educational radio), as well as the decades worth of research into how to deliver learning using those mediums, to provide a greater continuity of learning than what was seen in most jurisdictions. How can the K-12 education system put into practice some of the lessons learned over the past three decades about effective online learning?

In this paper, we detail ongoing efforts in a graduate instructional technology course to improve the preparation of K-12 teachers to teach in an online environment. After reviewing the literature on the topic of online K-12 teacher preparation and providing an overview of past iterations of the study, we present findings from the fifth round of an action research project. Finally, we conclude with a discussion of the implications of our findings and how they can influence both future iterations of the study and teacher training for online learning in general.

\section{Literature Review}

Despite the growth in K-12 online learning, there is little evidence to support a comparable growth in teacher training for online learning. In 2016, Archambault and her colleagues found that only 15 of the 363 teacher education programs who responded to their survey $(4.1 \%)$ offered options for an online field experience. While this was an increase from Kennedy and Archambault's (2012) study examining the same question, the growth projection is paltry when compared to the demand for online options in K-12.

There are several reasons that could explain why demand exceeds the supply of qualified teachers. Graziano and Bryans-Bongey (2018) surveyed faculty and administrators in colleges of education regarding online teacher training in teacher preparation programs. Respondents recognized the need to incorporate online teaching into preparation programs but doing so in a way that did not further expand an already time-consuming preparation sequence was a barrier to implementation. Further complicating matters is the lack of standardized resources for teaching educators how to teach in an online environment (McAllister \& Graham, 2016), similar to the standardized structures of law schools, medical schools, and, to some extent, teacher preparation. In their review of ten states' standards and guidelines for online teaching endorsements, McAllister and Graham saw little evidence of standardized resources, despite the fact that these states were, for the most part, using common standards from which to build their programs. The authors also noted that while these ten states had endorsements, not every institution offered the endorsement as a program of study. Moore-Adams et al. (2016), in their literature review of studies examining online teacher preparation programs, found that many are not rooted in empirical evidence; rather, they are often just modified versions of traditional teaching practices. The authors lamented the absence of explicit instruction on the skill differences between online and faceto-face teaching.

Pulham et al. (2018) provided additional justification for the concerns raised by Moore-Adams and her colleagues. In their review of ten online and blended teaching competencies from various organizations, they classified $57 \%$ of the competencies as being applicable to any teaching modality (i.e., in-person, online, or blended). Put differently, these competencies were about good teaching in general rather than distinct competencies for an online environment. In a similar review, Pulham and Graham (2018) called for more attempts to validate these standards, as did Barbour et al. (2013). The lack of unique teaching standards for an online environment may confuse pre-service teacher educators, which, in turn, leads to a reluctance to dedicate class time to address teaching in the online environment. Further, in their case study examining the perceptions of administrators, teachers, and teacher educators of the online teaching endorsement in the state of Georgia, Pourreau and LokeyVega (2017) found that the participants felt that the standards aligned well with their expectations of what online teachers will face. However, they felt that the standards needed to pay more attention to the various roles in online learning (e.g., designers, mentors, instructors), the need to address misconceptions, and the need for flexibility when teaching online. This lack of an empirical basis for online teacher preparation is also noted by Barbour et al. (2020) and Larson and Archambault (2019).

Finally, teacher preparation faculty may also be unfamiliar and uncomfortable with developing online teaching skills in their students. Borup and Evmenova (2019) examined the effects of professional development for faculty preparing teachers in an attempt to increase familiarity with the medium. They stressed the importance of modeling good online teaching for the faculty in order for them to understand the skills needed to be successful. After participating in the professional development, faculty improved their scores on a survey aligned to the Technological Pedagogical Content Knowledge (TPACK) framework (Mishra \& Koehler, 2007). The authors also noted the steep learning curve that faculty who are not savvy with technology would face in making the shift to teaching online. 
In addition, studies examining efforts to prepare teachers to teach in an online environment have had varied results. For example, Cooper et al. (2020) outlined a three-semester sequence for increasing pre-service educators' efficacy in online teaching. Instruction and assignments were aligned to standards from the International Society for Technology in Education (ISTE), the National Education Association (NEA), as well as TPACK. The authors claimed that the program was successful based on, "grades, presentations, and student discussion" (p. 134), but provided little evidence to back the claim. Graziano and Feher (2016) conducted a qualitative study on the perceptions of pre-service teachers who did dual placements in online and traditional settings. Students generally reported that they enjoyed the online experience but reported that they did not anticipate the amount of work involved with online learning. Further, the authors recommended that online field placements need quality mentors and a thorough selection process for mentors, in addition to an overall increase in the awareness of online teaching standards. On a more positive note, Luo et al. (2017), as part of a design-based research study on increasing pre-service teachers' exposure to online teaching, examined data from 140 pre-service teachers, including surveys, perception papers and focus groups. The researchers attempted to increase the students' exposure to online learning by incorporating video observations and guest speakers as part of a course. They found that the exposure improved the overall perception of online teaching. The pre-service teachers saw the medium as having benefits with respect to flexibility, personalization, and a potentially better environment for some students who were having difficulty in a traditional setting. The pre-service teachers felt that student motivation and a lack of socialization were potential drawbacks to teaching online.

In summary, concerns about preparing teachers to teach online is now a decades-old phenomenon, going as far back as 2007, where Rice and Dawley found that less than $40 \%$ of all online K-12 teachers received any medium-specific training before beginning to teach online. Given these mixed results and the already full teacher preparation curriculum, many teachers enter the world of online teaching without any prior experience or training (Archambault \& Larson, 2015); thus, they have to gain training through their employer, continuing education, or a formal graduate degree or certificate. So, it is of little surprise that when the majority of the world's schools went remote in early 2020, teachers struggled tremendously. The need for better preparation is obvious, and while the aforementioned barriers will always exist, how can we work to improve online teacher preparation? Further, teacher experiences over the 2019-20 and 2020-21 school years have left a negative impression of online teaching (Pressley, 2021). While data collection for this study was conducted prior to the pandemic, information regarding changing teachers' perceptions of online learning could be useful in reversing this negative perception

\section{Methodology}

This study is a continuation of an action research project examining a graduate level course titled "Internet in the Classroom" at a Midwestern public university designated as a "Doctoral: Very High Research" by the Carnegie Foundation. The course has several units of study, including topics about today's student and the notion of generational differences, use of Web 2.0 tools in the classroom, and virtual schooling. This research study is primarily focused on the latter. The course is an elective for various graduate instructional technology degrees at the institution, and is a requirement for both a graduate certificate in online teaching and for the state's K-12 teaching endorsement in educational technology. The project has been an iterative cycle of data collection, analysis, and recommendations for improving the course. This study represents the fifth cycle of data analysis.

Similar to previous iterations of the study, the purpose was to continue to explore the following questions:

1. What are in-service teacher perceptions of K-12 online learning?

2. How do those perceptions impact future curricular design of the course?

The first research question, first proposed during the initial iteration of the study (Barbour \& Harrison, 2016), was essentially a replication of Compton et al. (2007). In subsequent course offerings, action research became a focus; thus, the second research question was added. Action research is an appropriate methodology due to the fact that the very nature of improving educational practice is rooted in a continual cycle of data collection, analysis, and revision (Craig, 2009; Kermis \& McTaggart, 2008; Stringer, 2004).

\section{Summary of Changes to the Course}

After examining the artifacts and student evaluations in the first iteration of the course, the instructor increased the time spent on the online learning portion of the course, emphasizing the three roles of the virtual school teacher (Barbour $\&$ Harrison, 2016). Results from the second iteration suggested that more contextualized examples be included (i.e., the scenarios and case studies were from other states; perhaps local examples would be preferable). The third iteration was offered in a shortened summer term and allowed for adjustments in assignment requirements and blog post prompts (Barbour \& Siko, 2020). During the fourth iteration, state-specific examples were included in the curriculum, 
mirroring TEGIVS to reflect how local onsite facilitators mediate student learning (Azukas \& Barbour, 2021). In this iteration, in addition to the local facilitator scenarios, a series of case studies for the online teacher were developed based on Michigan examples (i.e., comparable to the ILO scenarios from previous iterations).

\section{Data Collection}

As with previous iterations of the study, data sources included course artifacts and student evaluations. Course artifacts included seven reflective blog posts as well as two assignment submissions. The blog posts were a way of conducting course discussions using a Web 2.0 tool (i.e., a blog) rather than a traditional discussion forum on a learning management system; the intention being to model usage of Web 2.0 tools since the topic was a unit of study in the course. Weekly prompts were provided by the instructor on his personal blog with the instructions to students to base their initial post on the prompts. Then, discussions occurred through commenting and responding on the blogs of classmates. Finally, course evaluations were administered near the end of the semester and consisted of both selectedresponse, Likert-style questions and open-ended constructed response questions. Evaluations are optional for students to complete.

\section{Data Analysis}

Having obtained continuing approval from the Institutional Review Board, students were informed of the research project at the beginning of the semester and provided with the appropriate consent forms. Five students were enrolled in the course, and all five consented to having their data included in the analysis. By comparison, course enrollments in previous iterations averaged between 10 and 16 students, with between 4 and 10 consenting to the study. The students, four females and one male, were all enrolled in various graduate programs in instructional technology at the university (one doctoral, one educational specialist, and three master's). Pseudonyms were used when preparing the data for analysis. Data from the blog posts and subsequent discussions, along with the assignment submissions, were analyzed using a constant comparative method (Strauss \& Corbin, 1994). Data were open coded after an initial reading by the researchers, and codes were refined over multiple reviews of the data until agreed upon themes emerged. In addition to multiple readings by multiple researchers, trustworthiness was further enhanced by comparing data and themes from the assignment submissions from students. Creswell (2003) discussed how multiple data sources and multiple researchers can lead to increased trustworthiness in the data analysis.
Finally, descriptive statistics from the Likert-style course evaluation questions were reviewed.

\section{Results}

Student evaluation scores for the course indicate that the course was well received. Four of the five students completed the evaluation. The university evaluation form ranks questions on a scale of 1 (poor) to 5 (excellent), and almost every question had a mean rating of 4.0 or higher. Along with the standard questions provided by the university, the instructor has the option of adding supplemental questions to gain additional information from students. However, for reasons of privacy, the university does not release the responses to these questions when fewer than five students in the course complete the evaluation, which was the case for this course. After completion of the initial round of coding and review by the researchers, several themes emerged from the student data. Regarding the first research question on in-service teacher perceptions of K-12 online learning, two themes emerged: an overall weak prior knowledge of the online learning world and the appropriateness of the medium given a particular context. In addition to these first two themes, another two themes emerged concerning the second research question on course impacts: soft skills that impact online learning success and the roles various adults play on the life of an online student.

\section{Lack of Awareness of the Online Learning Landscape}

The students in the course were generally unfamiliar with online teaching. None of the students had taught in an online environment before. Further, many of the students were unaware that the state had an online learning requirement despite the rule being in place for several years. The first blog prompt had two parts. First, students were asked for their thoughts before completing the assigned readings about online learning. The second part asked to reconcile their initial beliefs with their learning. Initially, the students' perceptions usually captured one facet of online learning. For example, Annette stated:

In a typical day, I presume that online learning has a very flexible schedule, and students are allowed to work at their own pace instead of the pacing systems that are evident in schools. Also, students will have the luxury of learning from home and at school as well. Special computer labs and/or classrooms are created and utilized for this online learning purpose. There are no set schedules with the exception that students must physically check-in with their teachers at least once weekly and participate on discussion boards daily. 
While highlighting the flexibility, she did not mention anything about synchronous learning, whereas Louie wrote:

I assume the teacher is in an office or at home with a headset and computer. The student might be at home or at school in a computer lab. The class would be accessible at any time of the day.

To which Sharon replied:

I was interested in your vision of the teacher in an office at their computer with a headset. In this scenario, is the instructor delivering a lecture or would there be some interactions with their students?

Again, these were initial thoughts with little to no background knowledge on the subject. After completing the assigned readings, many of the students stated that they did not realize the extent online learning was expanding in the United States. Further, they discussed their limited experiences both in K-12 and in their own online learning. For example, Karen responded to a statement in an article about the myths of online learning regarding interactions and isolation:

In my own experience, my online courses have indeed lacked interaction. The only interaction I've had has been strictly about the particular assignment. It has also seemed very forced and ingenuine.

However, one collective point of agreement among the students was the dispelling of the myth that online learning is only for gifted and talented students. Paul summarized this by stating:

A few of my preconceived notions were in direct opposition to some of the myths. I believe that online learning has the potential to be beneficial to a diverse amount of individuals and not just for gifted and talented students. Virtual schooling can be beneficial for those who have not seen success in the brick-andmortar classroom. I also believe the online classroom, much like the brick-and-mortar classroom has the potential for high and low levels of engagement.

With that said, there was some discussion of whether some students or courses were not suited for online learning, which was the second theme that emerged from the data.

\section{Age and content appropriateness}

Several students, upon learning about the scope of online learning, felt some trepidation regarding the appropriateness of online learning for a particular course or demographic. Some felt that online learning was inappropriate for younger learners, although there was disagreement based on the fact that learner attributes vary widely for a given age group.

With respect to subjects, the students discussed their evolving opinions of an online physical education course. In addition, Annette spoke at length about her opinions regarding an online public speaking course:

It has been argued that public speaking cannot be taken online because of the absence of an audience. As a college public speaking instructor, I once bought into this school of thought. However, since being exposed to virtual schooling and various technologies, my position has changed. A video could be created to show what virtual schooling in a public speaking classroom possibly looks like. The video could include: sample speech outlines via Camtasia, sample instructor speeches via YouTube, student speeches uploaded via a Ustream video (Students would have to pan over and show evidence that they are delivering their speech to an audience and not simply talking to a camera.), etc.

However, most of the discussion focused on at what age is online education appropriate. There was some relative debate on how appropriate online learning was for younger students. However, most were quick to caveat their statements with an understanding that a group of students of the same age would have a range of abilities to handle the online environment. Paul, Annette, and Sharon had this discussion based on Annette's initial posting:

Although, many believe that younger learners are at a technological advantage. Yet, without the soft skills, their technological "know-how" will still limit their online learning success.

I conclude that age is not a determinant for online learning success rather than a set of soft and technological skills that online learners must possess and utilize.

Paul - The "soft skills" necessary for online success require a lot from the learner. Are our are younger learners just developing these skills or fully capable and ready to apply them? Is it fair to hold them fully accountable for these "soft skills?" If so, how can we support them? If not, at what age do we expect full application?

Annette - If we begin teaching soft skills in upper elementary school-e.g., students using planners to manage their time-then we can expect complete development by high school. When students attend postsecondary school or have online courses, then we can be confident that their soft skills are working towards their advantage.

Sharon - Annette and Paul, Annette's statement implying we all know adult learners who are not self starters 
and are not motivated is quite the understatement:) If all adults were motivated to learn, the world would be a different place and competition would be fierce:) But I do believe age can somewhat determine online learning success as indicated in my post.

This discussion continued on as an example of the next major theme, soft skills and the responsibility for student development of these skills.

\section{Soft Skills}

Related to the notion of age appropriateness was the role soft skills play in online learner success. In the previous section, the students in the course were well aware of the notion that "age is just a number;" there are young students who exhibit these attributes and there are adult learners who have underdeveloped skills that present challenges to their success in an online classroom. The previous discussion then shifted to one of responsibility; that is, what are the expectations for developing these skills in early grades:

Sharon - Paul's questions make me think deeper about the issues our young online learners face in an online environment. Educators should be a big influence on how their study and writing skills evolve. I think about mentors in my academic and professional career and I realize I have been able to obtain soft skills for most of my life. This puts me at an advantage, but I must be willing to put these skills to work. Often times the content doesn't seem relevant to young learners and it's easy for them to get away. We as educators should influence them to look ahead and value success on all levels. Online facilitators also have the task of making the content seem interesting for younger learners, but there is not necessarily a certain age where we should expect full application of soft skills.

Annette - I think that many of our students are aware of soft skills, e.g., time management, but are not utilizing them to their advantage, which cripples their success in school.

Paul - I would like to restate my question. Should we expect elementary students to fully apply the skills necessary for online learning? Which should be taught first? How?

Annette - I don't think that elementary students can FULLY apply soft skills; however, we can begin the process with them. First, we can teach them to use their planners to develop their time management skills and build their other soft skills from there.

Specifically, when I was a principal I used planners with my upper elementary students. By the time they reached junior high, their soft skills were more evident.
Louise - Yes, younger students, i.e., elementary and middle school, are at a technological advantage, but so are the majority of students enrolled in $\mathrm{K}-12$ education. I agree that soft skills and technological skills, in addition to parent involvement and teacher mentoring are essential in online learning success.

Annette - Yes, Louise, students do need that wraparound system-parental and teacher support-in order for them to be successful online learners.

Karen - Annette, I could not agree more with your post.

Many people would think that older learners would possess those soft skills more so than younger learners, but that is not necessarily the case.

Maybe it depends on the students' earlier teachers' expectations of them. Were they taught the skills? Were they expected to use them so that they became inherent? That would seem to help students be more successful online learners.

Annette - Our students will rise to our level of expectations. If we expect little, they will deliver little. If we expect greatness, they will deliver greatness or very close to it.

To summarize, the students in the course generally agreed that the development of the soft skills necessary for success in online environments was not necessarily age-dependent. However, as the next theme details, the responsibility for fostering the development of these skills fell to the adults in the online student's life.

\section{Adult Roles in Online Learning}

As the semester progressed and students began to look at various online learning scenarios, they became more aware of the roles that adults play in the success of the online learner other than the teacher. This was true with respect to the previous themes of age and soft skills, as Louise stated:

I agree wholeheartedly with your assessment of age being a determinant of success in online learning. I observed in the videos of how virtual schooling is being used in other states with younger students that the parents are essential in the success of younger students in their online learning. I believe that older students need mentoring from their onsite teacher to help them be successful in online learning, even if they have the requisite soft skills.

Karen later discussed how a facilitator would have helped in a scenario where the student became anxious during her experiences in an online course:

As a school-based teacher, I would walk Susan through the course to show her how the course was laid out 
on the website. I would show her where the important information was located. This would allow me to be a guide and a mentor for her throughout the course.

Finally, at the conclusion of the course, many of the students felt more confident in their abilities as a facilitator, often more so than their confidence as an instructor or designer. Karen gave a succinct example:

I have more confidence in facilitating an online course with a student or group of students than to create one. Now that I have had experience with online courses and virtual schooling, I understand more of what they are about and how they typically work. Therefore, I think I could mentor other students through the process.

This better understanding of the roles also played out in the student artifacts. One of the course assignments was to develop a presentation for an imagined school board that demonstrated the need for continued support for online learning. Louise, Karen, and Sharon's submission went into great detail about the importance of the facilitator, and how their onsite presence can greatly improve student outcomes:

An obvious aspect to the role of an on-site facilitator is maintaining and troubleshooting for computers... Onsite facilitators also act as advocates for students. They serve as the online students' voice with school officials by making sure they have all resources necessary and reporting grades. They also communicate with parents. The facilitators can ensure parent understanding of the online learning process, as well as communicate student progress... Lastly and most importantly, on-site facilitators help students to develop soft skills necessary for success in an online environment.

Given the initial lack of awareness of the extent of online learning at the beginning of the course, it does seem reasonable that by the end, the students in the course would at least feel comfortable acting as a facilitator. Perhaps one semester is too short of a time to go from where they started to feeling comfortable with design and delivery.

\section{Discussion and Implications}

As an action research study, the goal of this line of inquiry is a systematic improvement to a localized problem (Craig, 2009; Kermis \& McTaggart, 2008; Stringer, 2004). As such, the ability to easily generalize to other contexts is questionable. As such, the purpose of the discussion is not only to share findings but to provide information readers to determine whether specific findings are applicable in their situations. Additionally, as with previous iterations, small class size and the lack of qualitative data reduced the usefulness of course evaluation data. While students appeared to approve of the course, the lack of context via open-ended responses, a small sample size, and the general weaknesses associated with student evaluations lend little to our understanding of the experience (Ambady \& Rosenthal, 1993).

Based on the findings of Luo et al. (2017) and Borup and Evmenova (2019), in addition to modeling online experiences, having actual observations in K-12 online courses or guest speakers with whom students could interact could further improve overall satisfaction with the course and content. With that said, as we emerge from the COVID-19 pandemic, virtually every in-service teacher will have had real-world experience with online teaching. On one hand, this may negate the need for additional exposure to online situations. On the other hand, what most teachers experienced in 2020 and 2021 was more aligned to what some have called emergency remote teaching (Hodges et al., 2020); and exposure to a well thought out, adequately planned and resources experience that was not reactive in nature could help to mitigate teachers' negative experiences during that time. With respect to the themes that emerged, we acknowledge that because the data were collected prior to the pandemic, the interpretations become more nuanced for several reasons. First, almost every teacher experienced remote teaching using online tools in some way in 2020 and 2021. As such, a total lack of awareness for K-12 online learning seems highly unlikely. Even as we emerge from the worst of the pandemic, many districts should consider future plans for virtual options moving forward (Barbour et al., 2020).

Similarly, since the entire spectrum of K-12 students shifted to remote learning, discussions about the possibility of teaching certain courses or age groups will likely be more muted. Quality and outcomes aside, teachers found ways to teach every grade and every subject remotely. With that said, teachers can still discuss whether it is appropriate to teach certain ages or certain subjects online and achieve the same level of quality instruction as they could in an inperson environment. Still, as Pulham and Graham (2018) and Pulham et al. (2018) point out, since many of the online teaching competencies could be summarized as just good teaching, one could reasonably expect that for the most part, good in-person teachers did a better job teaching remotely than less effective in-person teachers, regardless of age or content area. Further, it became clear that certain groups of students thrived in an online environment while others struggled. Much like Barbour and Reeves (2009) detailed how online courses are often geared toward a particular student profile, those students whose profile matched the instruction likely belonged to that successful group. The students in this course shifted their discussions of age appropriateness to a discussion of the necessary soft skills for success in online environments. 
Next, many teachers tried their best to simply replicate their in-person instruction to an online setting (Cheng, 2020). The students in this course seemed to not address different pedagogies for online learning. There is still a dearth of research discerning online from traditional pedagogies, and Moore-Adams et al. (2016) noted how this is a problem with current online teaching endorsements. This problem of a lack of online pedagogy became quite apparent during the pandemic, when so many teachers engaged in remote teaching by attempting to replicate their classroom teaching in Zoom - often referred to as 'Zoom school' (Barbour \& LaBonte, 2020; de Vries, 2021). Similarly, many school and district leaders were primarily concerned with the amount of face time between students and teachers as a measure of whether "teaching" was happening (Barbour et al., 2020). While the course in this study had separate units on Web 2.0 tools and online learning, there was little overlap with student assignments, as well as a lack of online pedagogies discussed in the course, with much of the discussion revolving around the various actors in an online course.

Finally, the students also reflected on the different roles in online learning. Both the reflective posts from the students and their artifacts demonstrated a solid understanding of the importance of teachers, mentors, and parents in the success of the online student. Compared to the findings of Pourreau and Lokey-Vega (2017), the fact that this course addressed these roles and the findings that demonstrate the students in the course understand them can be seen as a positive outcome. During the pandemic, when teaching shifted to remote teaching, the lack of resources and infrastructure with respect to human capital prevented schools from developing these roles. As such, teachers were tasked with doing all of them. As Pourreau and Lokey-Vega noted, teachers longed for additional information about these roles, but schools, even if they had the proper resources, would have been unaware of best practices in deploying additional staff to these roles. Howard, Tondeur, Siddiq, and Scherer (2021) indicated that teachers who may have fallen in the lower categories on their self-reported online readiness would have had additional difficulties.

\section{Conclusion}

In this paper, we detailed the findings of the fifth cycle of action research examining student perceptions about K-12 online learning in a graduate course. As with the previous iterations, the majority of themes were derived from the blogs posts of students, with some support from assignment artifacts and little to no support from student course evaluations. As such, future iterations should continue to adjust blog prompts to encourage better discussion of themes that have been consistent in each of the previous iterations. Further, we can also look to adjust the course assignments related to online learning to help the learners become more comfortable in not just facilitating courses, but also designing and teaching online courses.

As previously stated, broad recommendations from an action research study should be taken with a grain of salt. While the application of the knowledge gained may only apply to this situation, we highly encourage the use of action research to systematically update a course to meet the needs of changing student dynamics. With that said, data collection occurred prior to the pandemic, the themes found in the data support both changes to the course as the primary goal for the action research project, but also for preparing online teachers in general. The pandemic introduced an additional set of variables to consider moving forward with changes to the course, and future students will likely be more aware of the inner workings of online learning. However, their experiences may have likely been more negative than positive, so the introduction of live observations and guest speakers may be beneficial. Finally, continuing to advocate for online learning policy with respect to ensuring that adequate support is available for online learners, as well as proper training for teachers and facilitators, is crucial to the success of online students in the future.

\section{Declarations}

The authors of this paper have no conflicts of interest, financial or otherwise, related to the research conducted in this paper. All human subjects provided informed consent to have their data included in the study along with an opportunity to decline to have their data included in the analysis.

\section{References}

Ambady, N., \& Rosenthal, R. (1993). Half a minute: Predicting teacher evaluations from thin slices of nonverbal behavior and physical attractiveness. Journal of Personality and Social Psychology, 64(3), 431-441.

Archambault, L., Kennedy, K., Shelton, C., Dalal, M., McAllister, L., \& Huyett, S. (2016). Incremental progress: Re-examining field experiences in K-12 online learning contexts in the United States. Journal of Online Learning Research, 2(3), 303-326.

Archambault, L., \& Larson, J. (2015). Pioneering the digital age of instruction: Learning from and about K-12 online teachers. Journal of Online Learning Research, 1(1), 49-83.

Azukas, M. E., \& Barbour, M. K. (2021). In-service teachers' perceptions of K-12 online learning curriculum in a graduate course: An action research project. International Journal of Online Pedagogy and Course Design, 11(4), 61-81. https://doi.org/10.4018/ IJOPCD.2021100105

Barbour, M. K. (2020). Misbehaving toddler or moody teenager: Examining the maturity of the field of K-12 online learning. Revista de Educación a Distancia, 64(20). Retrieved from https://revistas. um.es/red/article/view/412821/286721. Accessed 25 Oct 2021. 
Barbour, M. K. (2019). The landscape of K-12 online learning: Examining what is known. In M.G. Moore \& W.C. Diehl (Eds.) Handbook of Distance Education (4th ed.) (pp. 521-542). New York: Routledge.

Barbour, M. K., \& Harrison, K. U. (2016). Teachers' perceptions of K-12 online: Impacting the design of a graduate course curriculum. Journal of Educational Technology Systems, 45(1), 74-92. https://doi. org/10.1177/0047239516637072

Barbour, M. K., \& LaBonte, R. (2020). Stories from the field: Voices of $K-12$ stakeholders during pandemic. Canadian eLearning Network. https://sites.google.com/view/canelearn-ert/. Accessed 25 Oct 2021.

Barbour, M. K., LaBonte, R., Kelly, K., Hodges, C., Moore, S., Lockee, B., Trust, T., Bond, A., \& Hill, P. (2020). Understanding pandemic pedagogy: Differences between emergency remote, remote, and online teaching. Canadian eLearning Network. Retrieved from https://k12sotn.ca/wp-content/uploads/2020/12/understandingpandemic-pedagogy.pdf. Accessed 25 Oct 2021.

Barbour, M. K., \& Reeves, T. C. (2009). The reality of virtual schools: A review of the literature. Computers \& Education, 52(2), 402-416. https://doi.org/10.1016/j.compedu.2008.09.009

Barbour, M. K., \& Siko, J. (2020). Advancing a curriculum toward improved online nurturing of K-12 students. i-Manager's. Journal of Educational Technology, 16(4), 20-32.

Barbour, M. K., Siko, J., Gross, E., \& Waddell, K. (2013). Virtually unprepared: Examining the preparation of K-12 online teachers. In R. Hartshorne, T. Heafner, \& T. Petty (Eds.), Teacher education programs and online learning tools: Innovations in teacher preparation (pp. 60-81). IGI Global.

Cavanaugh, C., \& DeWeese, A. (2020). Understanding the professional learning and support needs of educators during the initial weeks of pandemic school closures through search terms and content use. Journal of Technology and Teacher Education, 28(2), 233-238.

Cheng, X. (2020). Challenges of'school's out, but class's on'to school education: Practical exploration of Chinese schools during the COVID19 Pandemic. Sci Insigt Edu Front, 5(2), 501-516.

Cooper, R., Farah, A., \& Mrstik, S. (2020). Preparing teacher candidates to teach online: A case study of one college's design and implementation plan. International Journal on E-Learning, 19(2), 125-137.

de Vries, T. J. (2021). The pandemic that has forced teachers to go online: Zooming in on tips for online teaching. Frontiers in Education, 6(647455). https://doi.org/10.3389/feduc.2021.647445

Diliberti, M. K., \& Kaufman, J. H. (2020). Will this school year be another casualty of the pandemic? Key findings from the American educator panels fall 2020 COVID-19 surveys. RAND Corporation. https://www.rand.org/pubs/research_reports/RRA168-18html

Engzell, P., Frey, A., \& Verhagen, M. D. (2021). Learning loss due to school closures during the COVID-19 pandemic. Proceedings of the National Academy of Sciences, 118(17) Retrieved from https:// www.pnas.org/content/pnas/118/17/e2022376118.full.pdf. Accessed 25 Oct 2021.

German, E. (2020). Distance learning has been part of American culture for 100 years. Why can't we get it right? GEN: Medium. Retrieved from https://gen.medium.com/distance-learning-has-been-part-ofamerican-culture-for-almost-100-years-e3c001a05858. Accessed 25 Oct 2021.

Graziano, K. J., \& Bryans-Bongey, S. (2018). Surveying the National Landscape of Online Teacher Training in K-12 Teacher Preparation Programs. Journal of Digital Learning in Teacher Education, 34(4), 259-277. https://doi.org/10.1080/21532974.2018.1498040

Graziano, K. J., \& Feher, L. (2016). A dual placement approach to online student teaching. Contemporary Issues in Technology and Teacher Education, 16(4), 495-513.

Kennedy, K., \& Archambault, L. (2012). Offering preservice teachers field experiences in K-12 online learning: A national survey of teacher education programs. Journal of Teacher Education, 63(3), 185-200. https://doi.org/10.1177/0022487111433651
Hodges, C., Moore, S., Lockee, B. Trust, T., \& Bond, A. (2020). The Difference Between Emergency Remote Teaching and Online Learning. Educause. https://er.educause.edu/articles/2020/3/the-diffe rence-between-emergency-remote-teaching-and-online-learning. Accessed 25 Oct 2021.

Howard, S. K., Tondeur, J., Siddiq, F., \& Scherer, R. (2021). Ready, set, go! Profiling teachers' readiness for online teaching in secondary education. Technology, Pedagogy and Education, 30(1), 141-158. https://doi.org/10.1080/1475939X.2020.1839543

LaBonte, R., Barbour, M. K., \& Nagle, J. (2021). Pandemic pedagogy in Canada: Lessons from the first 18 months. Canadian E-Learning Network. https://secureservercdn.net/198.71.233.30/sgf.292.myftp upload.com/wp-content/uploads/2021/11/CANeLearn-PandemicPedagogy-in-Canada.pdf. Accessed 2 Jan 2022.

Larson, J. S., \& Archambault, L. (2019). The extent of K-12 online teacher development: A disconnect between preparation and practice. In T. Heafner \& R. Hartshorne (Eds). Handbook of research on emerging practices and methods for $\mathrm{K}-12$ online and blended learning (pp. 57-77). Hershey, PA: IGI Global.

Luo, T., Hibbard, L., Franklin, T., \& Moore, D. R. (2017). Preparing teacher candidates for virtual field placements via an exposure to $\mathrm{K}-12$ online teaching. Journal of Information Technology Education: Research, 16, 1-14. doi: 10.28945/3626

McAllister, L., \& Graham, C. (2016). An analysis of the curriculum requirements for K-12 online teaching endorsements in the US. Journal of Online Learning Research, 2(3), 247-282.

Mishra, P., \& Koehler, M. (2007). Technological pedagogical content knowledge (TPCK): Confronting the wicked problems of teaching with technology. In C. Crawford et al. (Eds.), Proceedings of Society for Information Technology and Teacher Education International Conference 2007 (pp. 2214-2226). Association for the Advancement of Computing in Education.

Moore-Adams, B. L., Jones, W. M., \& Cohen, J. (2016). Learning to teach online: A systematic review of the literature on K-12 teacher preparation for teaching online. Distance Education, 37(3), 333-348. https://doi.org/10.1080/01587919.2016.1232158

Pourreau, L., \& Lokey-Vega, A. (2017, March). Perceptions of K-12 online teaching endorsement program effectiveness in Georgia: A case study. In P. Resta \& S. Smith (Eds.), Society for Information Technology \& Teacher Education International Conference 2017 (pp. 685-691). Association for the Advancement of Computing in Education.

Pulham, E., \& Graham, C. R. (2018). Comparing K-12 online and blended teaching competencies: A literature review. Distance Education, 39(3), 411-432. https://doi.org/10.1080/01587919.2018.1476840

Pulham, E. B., Graham, C. R., \& Short, C. R. (2018). Generic vs. modality-specific competencies for K-12 online and blended teaching. Journal of Online Learning Research, 4(1), 33-52.

Pressley, T. (2021). Factors contributing to teacher burnout during COVID-19. Educational Researcher, 50(5), 325-327. https://doi. org/10.3102/0013189X211004138

Rush, S. C., Partridge, A., \& Wheeler, J. (2016). Implementing emergency online schools on the fly as a means of responding to school closures after disaster strikes. Journal of Educational Technology Systems, 45(2), 188-201.

Schroeder, B. (2019). Disrupting education: The rise of K-12 online and the entrepreneurial opportunities. Forbes. Retrieved from https:// www.forbes.com/sites/bernhardschroeder/2019/08/14/disruptingeducation-the-rise-of-k-12-online-and-the-entrepreneurial-oppor tunities. Accessed 25 Oct 2021.

U.S. Department of Education, Office of Educational Technology (2017). Reimagining the role of technology in education: 2017 national education technology plan update, Washington, D.C.

Publisher's Note Springer Nature remains neutral with regard to jurisdictional claims in published maps and institutional affiliations. 